\title{
Preventive security measures for the public passenger transport system operation based on logistic management principles
}

\author{
Tatiana Shulzhenko ${ }^{1 *}$ \\ ${ }^{1}$ Saint-Petersburg State University of Economics, 191023 St. Petersburg, Russia
}

\begin{abstract}
You should leave $8 \mathrm{~mm}$ of space above the abstract and $10 \mathrm{~mm}$ after the abstract. The heading Abstract should be typed in bold 9-point Arial. The body of the abstract should be typed in normal 9-point Times in a single paragraph, immediately following the heading. The text should be set to 1 line spacing. The abstract should be centred across the page, indented $17 \mathrm{~mm}$ from the left and right page margins and justified. It should not normally exceed 200 words.
\end{abstract}

\section{Introduction}

Urban public passenger transport (PPT) safety system operation is the key complex quality indicator substantially determining the efficiency of the taken decisions in the frame of management and development goals of the urban environment. Under the present -day conditions, an indispensable prerequisite of the city transport system integrity safety with its specific place among the factors of the perspective economic, social, spatial development of the urban environment, ensuring its balanced development and maintenance of the (PPT) services quality level meeting consumers requirements is the development of mechanisms and procedures of planning, organizing, stimulating, regulating and controlling of the whole urban PPT system on the single principles focused on a qualitative component of its operation $[1]$.

Provided by the Russian Federation legislation, the mechanisms of normative and legal regulation of the activity organized in the field of passenger traffic $[2,3]$, have a sufficient potential for the integrated approach to ensure the given level of quality for PPT urban system operation. In particular, in the system of the State contract (further- SC) on rendering services to ensure population transport service by the public motor transport on the routes of scheduled passenger traffic and baggage, quality indicators perform a particular function - allow to set the required level of PPT quality (in general) by means of legal relationship system "Customer - Carrier". At the same time, the Customer role (the city Administration) is to form a city requirements complex to services quality accounting for the current and perspective development priorities of the urban environment, citizens social security $[4,5,6$, 7] on which the scientific and methodical justification as a purpose of the conducted research is based.

*Corresponding author: shul-tatiana@yandex.ru 


\section{Material and Methods}

As a result of synthesis of theoretical approaches to the urban public transport quality system formation based on the subject and categorial decomposition, the groups of factors and indicators for each level and system subject have been distinguished. It should be noted that the indicator "Complex safety" is referred to the factors of the first level conjugated with the system of purposes and functions of all main subjects of the urban PPT quality system. At the same time, it is obvious that attaching a particular importance to PPT city system operation safety, some preventive measures interfering with rendering of low-quality services when managing the given system by the transport enterprises (Carriers) at the stage of development and negotiating the State contract, have to be provided.

Further detailed elaboration of the "Complex safety" indicator allows specifying the factors of the second level resulted from the Administration (Customer) and transport enterprise (Carrier, or the Performer) activity that, in turn, enables: identify responsibility and content of the Administration tasks complex ensuring the city PPT quality within the frame of the State contract system; formulate the initial requirements to the State contract performer in the Specification; develop the indicators system and complex assessment of the State contract terms implementation by the transport enterprise, control the fulfillment of obligations which is recommended to be used at the stages:

- when selecting applicants for negotiating the State contract (for ensuring the set level of transport service quality for the population in the urban PPT system );

- estimating the fulfillment of obligations by the carrier under the State contract.

Thus, one of the main problems when developing a complex of preventive measures for the urban PPT safety system under the State contract is providing a complex of the clear and unambiguously defined indicators of the Carrier assessment. As it has been shown in [4], the research of substantial aspects of the urban PPT system operation allows consider it as a logistics system, and, we believe, when this system is managed effectively, logistic management tools presented in Shabanov [8], Gudkov, Mirotin,Velmojin [9], Lagorio, Pinto, Golini 10], Letnik, Marksel, Luppino, Bardi, Božičnik’s [11] works can be used.

In particular, when solving the problem of developing preventive security measures for PPT system operation, in our opinion, it is expedient to use general logic for the selection and assessment methods of the logistic intermediary activity. Then to solve the problem, the offered procedure of identifying the indicators system assessment comes down to the following sequence of stages:

1. Identifiying factors determining the quality of the urban PPT system operation in general;

2. Developing indicators determining the quantitative assessment of the given factors;

3. Developing the assessment technique of the Carrier compliance to "Complex safety" indicators.

At the stage of preliminary selection of applicants for negotiating the State contract, it is expedient to be guided by the constituents of quality indicators (by the "Complex safety" factor) which, in particular, are:

- indicators of the vehicles (V) operation reliability characterize the vehicle features providing, in their use, unfailing operation during the trip or other set time interval. Reliability indicators are: resource; service life; unfailing operation probabilities; time between failures; frequency of vehicle technical condition control by the state supervision bodies; existence of the document confirming the vehicle admission to operation;

- indicators of the professional suitability of the transport services performers. characterize special features of the enterprise- carrier personnel indicating its ability to provide passengers transportation according to passenger traffic safety requirements: length 
of service in this position; skill level (driving class); frequency of professional development; number of violations of the vehicles control rules and duty regulations for a certain period.

The specification of the constituents of the PPT system quality indicators is presented in Gudkov, Mirotin, Velmojin, Shiryaev [9], Frolov [12], Monzon, Hernandez, Cascajo [13], Oña, López, Rios, Oña [14], Wretstrand, Holmberg, Berntman [15], Alonsoa, Monzónb, Cascajoa [16], Tlegenov [17], Berežný, Konečný [18], Danilina, Elistratov [19], Ngoc, Hung, Tuan [20], Currie, Truong, De Gruyter [21], works.

The Carrier compliance assessment by safety indicators at the implementation stage of the State contract is offered to be carried out with a technique based on the created system of factors (fig. 1).

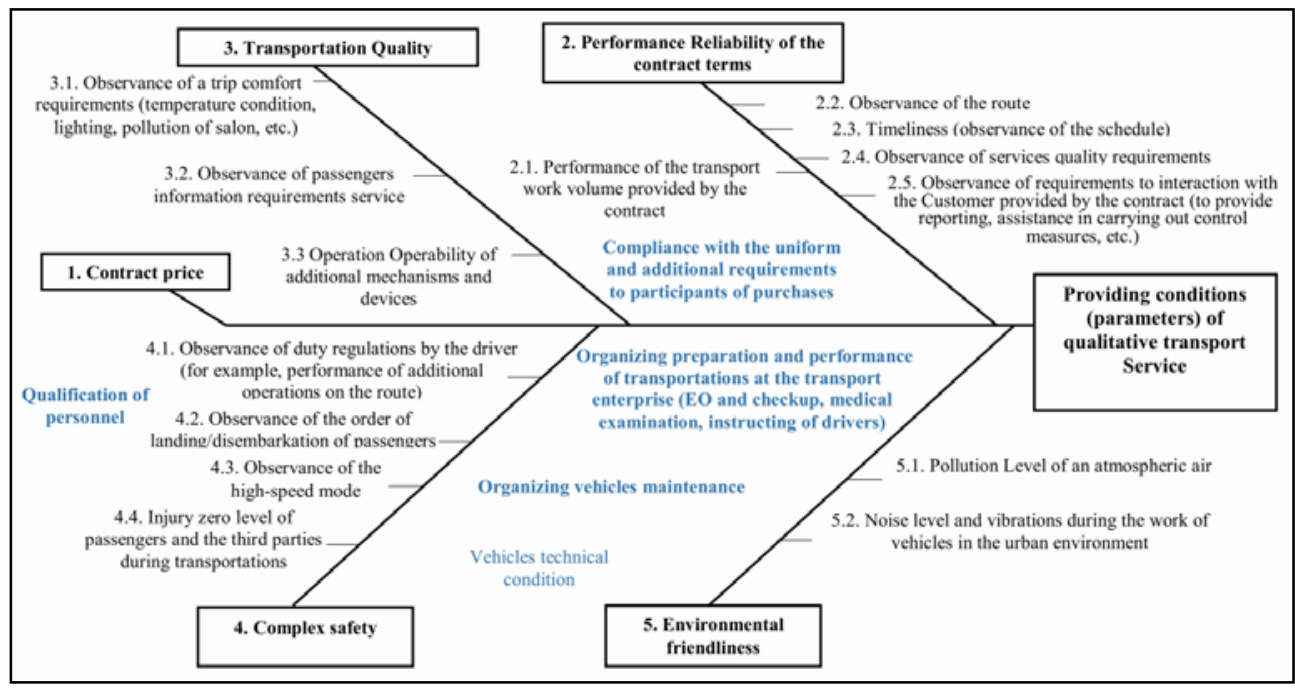

Fig. 1. The factors considered when assessing the carrier quality terms performance of the contract on rendering transportation services to population on the routes of regular transportation of passengers and baggage in urban traffic.

The system of factors presented in figure 1 is the basis for the formation of appropriate indicators of the quality of public passenger transport services in urban traffic.

\section{Calculation}

Further assessment of the quality of the Carrier's work involves the calculation of private quality indicators, as well as an integral indicator of quality.

The procedure for assessing the work of the Carrier includes the following sequence of stages:

1. Formation of the violation weight

$$
\omega_{i}=\frac{\Omega_{j} \omega_{i}^{j} n_{i}}{N}
$$

where $\omega_{i}-$ violation weight;

$\Omega j$ - the weight of $j$ complex quality indicator including the considered private indicator connected with a type of violation (described in an expert way by the paired comparisons method); 
$\omega_{i}^{j}$ - the weight of $i$ private indicator as a part of $j$ quality complex indicator (described in an expert way by the paired comparisons method);

$n_{i}$ - number of the private indicators in $j$ complex quality indicator;

$N-$ total of private indicators, $N=1 \ldots i$.

2. Ranging and grouping violations by the extent of influence on the integral quality indicator.

Ranging is carried out based on the weight violation size $\omega_{i}$.

As a result of grouping, $K$ group $(K=1 \ldots k)$ of indicators by the extent of influence on an integrated quality indicator is formed, at the same time $n_{k}$-number of private indicators in $k$ group. Group results are presented in table. 1.

Table 1. Description of private indicators group.

\begin{tabular}{|c|c|c|c|c|c|}
\hline $\begin{array}{c}\text { Indicat } \\
\text { ors } \\
\text { group } \\
\text { numbe } \\
\mathbf{r}(\boldsymbol{k})\end{array}$ & $\begin{array}{c}\text { Range of } \\
\text { values }\left(\boldsymbol{\omega}_{\boldsymbol{i}}\right)\end{array}$ & $\begin{array}{c}\text { Private } \\
\text { indicators } \\
\text { number in the } \\
\text { group }\left(\boldsymbol{n}_{\boldsymbol{k}}\right)\end{array}$ & $\begin{array}{c}\text { Group share } \\
\text { of private } \\
\text { indicators }\left(\boldsymbol{d}_{\boldsymbol{k}}\right)\end{array}$ & $\begin{array}{c}\text { Number of penal } \\
\text { points per } \\
\text { indicators group } \\
\left(\boldsymbol{S}_{\boldsymbol{k}}\right)\end{array}$ & $\begin{array}{c}\text { Number of } \\
\text { penal points } \\
\text { per violation } \\
\text { in indicators } \\
\text { group }\left(\boldsymbol{S}_{\boldsymbol{i}}\right)\end{array}$ \\
\hline 1 & till 0,005 & 7 & 0,07 & 7 & 1 \\
\hline 2 & $0,005-0,01$ & 9 & 0,157 & 16 & 2 \\
\hline 3 & $0,01-0,015$ & 8 & 0,271 & 27 & 3 \\
\hline 4 & over 0,015 & 3 & 0,502 & 50 & 17 \\
\hline
\end{tabular}

3. Distributing the sum of penal points by violations groups (indicators).

3.1. Determining the average weight of private indicators in $k$ group

$$
\bar{\omega}_{i}^{k}=\frac{\sum_{i} \omega_{i}^{k}}{n_{k}}
$$

where $\omega_{i}^{k}$ - the weight of $i$ private indicator as a part of $k$ group.

3.2. Determining the group of indicators share

$$
d_{k}=\frac{\bar{\omega}_{i}^{k}}{\sum_{i} \bar{\omega}_{i}^{k}}
$$

3.3. Distributing the penal points sum (100 points) in groups according to a certain size of an indicators group share

$$
S_{k}=100 d_{k}
$$

where $S_{k}$ - number of the penal points falling on $k$ group of indicators.

3.4. Distributing points in the group by violations types (private indicators)

$$
S_{i}=\frac{S_{k}}{n_{k}}
$$

where $S_{i}$ - number of points for each type of violation.

4. Determining the penal points number charged for the i- kind violations

4.1. Determining basic value. As a basic value, it is offered to use the maximum possible number of facts (cases) of violations of i kind calculated with the following formulas: 


$$
N_{\max }=N_{\text {event }}^{\text {plan }} \cdot N_{v}
$$

where $N_{v}$ - planned number of vehicles on the line when the control is exercised;

$$
N_{\max }=T_{\text {event }}^{\text {plan }}
$$

where $T_{\text {event }}^{\text {plan }}$ - duration period of the planned control;

$$
N_{\max }=T_{\text {trip }}^{\text {plan }} \cdot L_{\text {trip }}^{\text {plan }}
$$

where $L_{\text {trip }}^{\text {plan }}$ - planned length of the trip.

4.2. Determining the number of the penal points charged for each discovered fact (case) of violation.

A number of penal points for each fact of violation is determined from the ratio of a number of points for each kind of violation to the basic value.

4.3. Determining the sum of penal points by each type of violations

There are the following formulas for calculating the sum of penal points for each type of violations based on the character of an indicator:

$$
b_{i}=\frac{S_{i} \cdot N^{\text {fact }}}{N_{\max }}, \text { or } b_{i}=\frac{S_{i} \cdot T^{\text {fact }}}{N_{\max }}, \text { or } b_{i}=\frac{S_{i} \cdot L^{\text {fact }}}{N_{\max }}
$$

where $N^{\text {fact }}$ - number of the discovered facts (cases) of $i$ kind violations; $T^{\text {fact }}$ - operating time duration with violations; $L^{\text {fact }}$ - length of the route site passed with violations; $N_{\max }$ - is determined from formulas (7) and (8) in the appropriate cases.

The results of the applied technique are presented in table 2.

5. Determining an integral quality indicator

The integral quality indicator is determined from the sum of the penal points for the revealed violations in the reporting period.

Table 2. Calculating the number of penal points for the discovered violations (a fragment)

\begin{tabular}{|c|c|c|c|c|}
\hline Code and name of violation & $\begin{array}{c}\text { Indicator } \\
\text { weight } \\
\left(\boldsymbol{\omega}_{i}\right)\end{array}$ & $\begin{array}{c}\text { Number of } \\
\text { points per } \\
\text { violation } \\
\left(\boldsymbol{S}_{\boldsymbol{i}}\right)\end{array}$ & $\begin{array}{c}\text { Base for } \\
\text { calculating } \\
\text { number of } \\
\text { points for } \\
\text { each fact of } \\
\text { violation }\end{array}$ & $\begin{array}{c}\text { Number of } \\
\text { points for } \\
\text { each elicited } \\
\text { fact of this } \\
\text { kind of } \\
\text { violation }\end{array}$ \\
\hline $\begin{array}{c}4.1 . \text { Use driving on the route } \\
\text { for other purposes }\end{array}$ & 0,008889 & 2 & Formula (7) & $\begin{array}{c}\text { According to } \\
\text { Formula (9), }\end{array}$ \\
\hline $\begin{array}{c}4.3 . \text { Exceeding speed limit of } \\
60 \mathrm{~km} / \mathrm{h} \text { or maximum vehicles } \\
\text { speed established by the road } \\
\text { signs located on the route, if } \\
\text { this speed is less than } 60 \mathrm{~km} / \mathrm{h} .\end{array}$ & 0,013333 & 3 & Formula (8) & $\begin{array}{c}\text { According to } \\
\text { Formula (9), }\end{array}$ \\
\hline
\end{tabular}

\section{Results and Discussion}

Thus, the implementation stage of the presented approach to developing the preventive measures providing a given level for a large city PPT operation is connected with a detailed study of the requirements to applicants for negotiating the State contract, and also a regular monitoring of Carriers terms fulfillment on the basis of the presented system of indicators with the subsequent application of responsibility measures in the case of their violation, for 
example, reduction of the payments size to carrier accounting for the quality coefficient size, imposing a penalty for terms violation of the State contract, and cancellation of the State contract.

The practical implementation of the presented methodology was partially reflected in the process of preparation of the draft State contract in St. Petersburg during 2016-2018. Partial implementation of the developed approach demonstrated positive changes in consumers' perception of the quality of public passenger transport services (fig. 2).

The next stage of practical implementation of the developed approach is related to the tender procedure in the public passenger transport system of St. Petersburg in 2019. Areas for further research are related to the collection and analysis of statistical data on the effectiveness of the proposed measures and also to the adjustment of the indicators used.

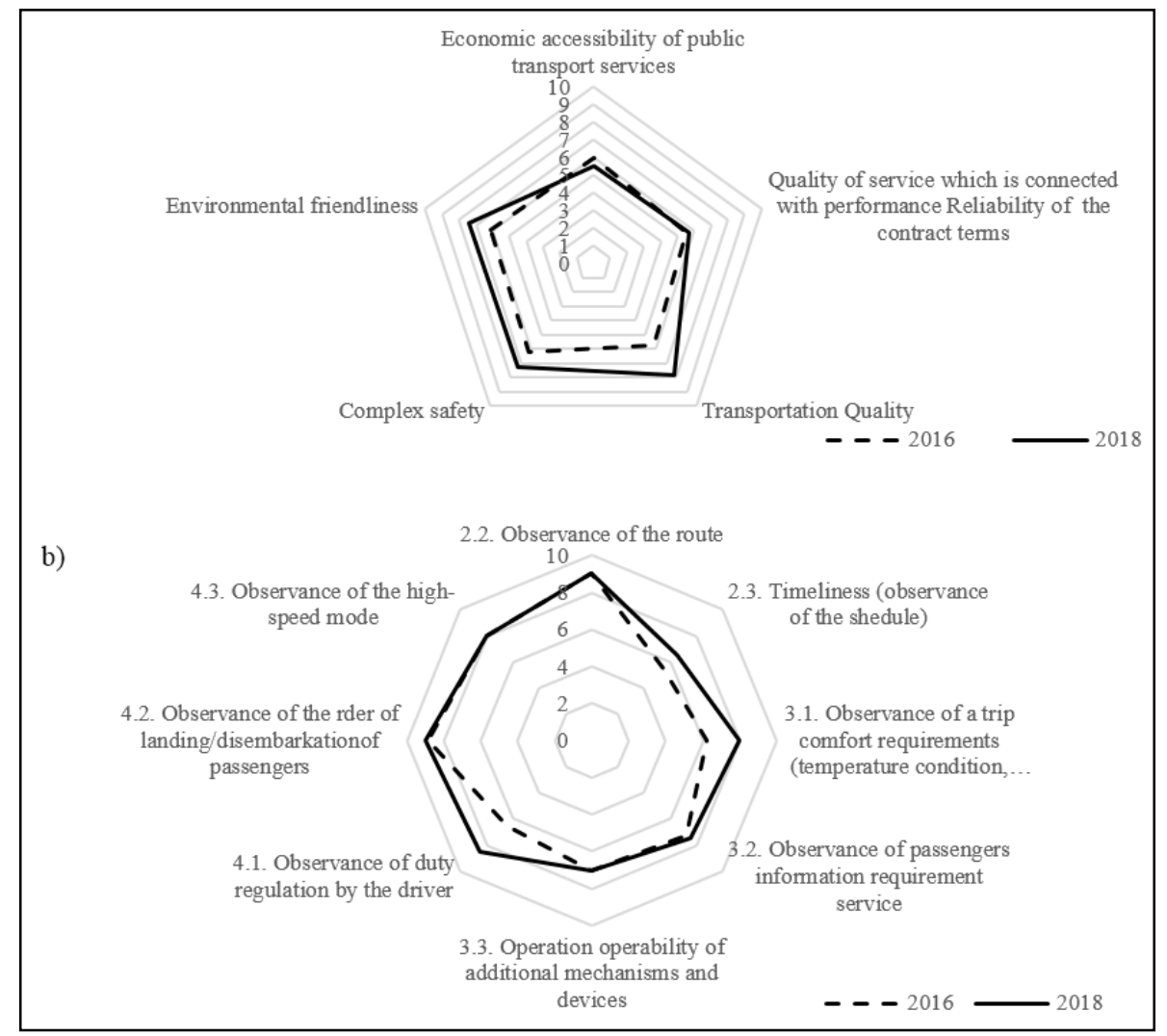

a) in General, the system of public passenger transport in St. Petersburg

b) related to the work of Carriers

Fig.2. The results of the implementation of preventive security measures for the public passenger transport system operation (view of consumers of public passenger transport services)

\section{References}

1. T G Shulzhenko, Methods for managing the services quality in the logistic system of public passenger transport in a large city, Logistic systems in the global economy: materials of the VII Intern. scientific-practical. conf. (March 14-15, 2017, Krasnoyarsk), pp. 372-377 (2017) 
2. Federal Law No. 44-FZ of 05.04.2013 ( amended on June 23, 2016) "On the contract system in the sphere of procurement of goods, works and services to ensure state and municipal needs" (with amendment and add., entry in force from 01.07.2016).

3. Federal Law \#. 220-FZ of July 13, 2015 "On the Organization of Regular Transportation of Passengers and Luggage by Road Transport and Urban Ground Electric Transport in the Russian Federation, and on Amending Certain Legislative Acts of the Russian Federation."

4. T G Shulzhenko, Application of logistics conceptual provisions to ensure the services quality of the public passenger transport system of a large city, St. Petersburg Logistics potential in the formation of innovative economy: Collection of abstracts of the Int. Scientific and Practical Conf., pp. 289-293 (2016)

5. V T Thao, P Wegelin and W Arx, Are statutory passenger watchdogs effective in representing passenger interests in public transport?, Transport Policy, 58, pp. 1-9 (2017)

6. A Ryzhkov, Local public transport in Russia: Regulation, ownership and competition, Research in Transportation Economics, 69, pp. 207-217 (2018)

7. W Veenemana and C Mulleyb, Multi-level governance in public transport: Governmental layering and its influence on public transport service solutions, Research in Transportation Economics, 69, pp. 430-437 (2018)

8. A V Shabanov, Regional logistic systems of public transport: methodology of formation and management mechanism, Rostov-on-Don: Publishing House of the SKNC V.S., p. 205 (2001)

9. V A Gudkov, L B Mirotin, A V Velmojin and S A Shiryaev, Passenger automobile transportation: a textbook for universities M.: Hot line-Telecom, p. 448 (2004)

10. A Lagorio, R Pinto and R Golini, Urban Logistics Ecosystem: a system of system framework for stakeholders in urban freight transport projects, Proc. of the 20th World Congress The International Federation of Automatic Control Toulouse, France, July 914, 2017. IFAC PapersOnLine, vol 50-1, pp. 7284-7289 (2017)

11. T Letnik, M Marksel, G Luppino, A Bardi and S Božičnik, Review of policies and measures for sustainable and energy efficient urban transport, Energy, 163, pp. 245257 (2018)

12. K V Frolov Formation of quality indicators and standards of urban bus transportation, The author's abstract of diss. Doct.thesis.: speciality 08.00.05 Moscow, p. 24 (2005)

13. A Monzon, S Hernandez and R Cascajo, Quality of bus services performance: Benefits of real time, passenger information systems, Transport and Telecommunication, 14 (2), pp. 155-166 (2013)

14. R.de Oña, G López, F J D de los Rios and J de Oña, Cluster analysis for diminishing heterogeneous opinions of service quality public transport passengers, XVIII Congreso Panamericano de Ingeniería de Tránsito, Transporte y Logística (PANAM 2014). Procedia - Social and Behavioral Sciences, vol 162, pp. 459 - 466 (2014)

15. A Wretstrand, B Holmberg and M Berntman, Safety as a key performance indicator: Creating a safety culture for enhanced passenger safety, comfort, and accessibility, Research in Transportation Economics, 48, pp. 109-115 (2014)

16. A Alonsoa, A Monzónb and R Cascajoa, Comparative analysis of passenger transport sustainability in European cities, Ecological Indicator, 48, pp. 578-592 (2015) 
17. B N Tlegenov, An analysis of evaluation methods and quality indicators of the urban passenger transport system, Modern problems of science and education, 9, pp. 1-9 (2012)

18. R Berežný and V Konečný The impact of the quality of transport services on passenger demand in the suburban bus transport TRANSCOM 2017: Int. scientific conf. on sustainable, modern and safe transport. Procedia Engineering vol 192, pp. 40 - 45 (2017)

19. N Danilina and D Elistratov, Organization of Municipal Transport Access Control System. Passenger Service Models, 12th Int. Conf. "Organization and Traffic Safety Management in large cities", SPbOTSIC-2016, 28-30 September 2016, St. Petersburg, Russia. Transportation Research Procedia, vol 20, pp. 132 - 137 (2017)

20. A M Ngoc, K V Hung and V A Tuan, Towards the Development of Quality Standards for Public Transport Service in Developing Countries: Analysis of Public Transport Users' Behavior, World Conf. on Transport Research - WCTR 2016 Shanghai. 10-15 July 2016. Transportation Research Procedia, vol 25, pp. 4560-4579 (2017)

21. G Currie, L Truong and C De Gruyter, Regulatory structures and their impact on the sustainability performance of public transport in world cities, Research in Transportation Economics, 69, pp. 494-500 (2018) 